\title{
MEMBANDINGKAN TINGKAT KEMIRIPAN REKAMAN VOICE CHANGER MENGGUNAKAN ANALISIS PITCH, FORMANT DAN SPECTOGRAM
}

\author{
Ahmad Subki ${ }^{1}$, Bambang Sugiantoro ${ }^{2}$, Yudi Prayudi ${ }^{3}$ \\ 1,3Magister Teknik Informatika, Fakultas Teknik Industri, Universitas Islam Indonesia Yogyakarta \\ ${ }^{2}$ Teknik Informatika UIN Sunan Kalijaga Yogyakarta \\ Email: 15917102@ students.uii.ac.id, ${ }^{2}$ bambang.sugiantoro@uin-suka.ac.id, ${ }^{3}$ prayudi@uii.ac.id
}

(Naskah masuk: 27 Oktober 2017, diterima untuk diterbitkan: 18 Pebruari 2018)

\begin{abstract}
Abstrak
Audio forensik merupakan salah satu ilmu yang mnyandingkan antara ilmu pengetahuan dan metode ilmiah dalam proses analisis rekaman suara untuk membantu dan mendukung pengungkapan suatu tindak kejahatan yang diperlukan dalam proses persidangan. Undang-undang ITE No.19 Tahun 2016 menyebutkan bahwa rekaman suara merupakan salah satu alat bukti digital yang sah dan dapat digunakan sebagai penguat dakwaan. Rekaman suara yang merupakan barang bukti digital sangatlah mudah dan rentan dimanipulasi, baik secara sengaja maupun tidak disengaja. Pada penelitian ini dilakukan analisis terkait tingkat kemiripan antara rekaman suara voice changer dengan rekaman suara asli menggunakan analisis pitch, formant dan spectogram, rekaman suara yang dianalisis ada dua jenis rekaman suara yaitu suara laki-laki dan suara perempuan. Rekaman suara voice changer dan rekaman suara asli, diekstrak menggunakan tools praat kemudian informasi yang diperoleh dianalisis dengan analisis statistik pitch, formant dan spectrogrammenggunakan tools gnumeric. Penelitian ini menghasilkan bahwa analisis rekaman suara voice changer dengan rekaman suara asli dapat menggunakan analisis statistik pitch, formant dan spectrogram, rekaman suara voice changer A memiliki tingkat kemiripan yang paling tinggi dengan rekaman suara asli pada posisi low pitch, sedangkan voice changer yang lain lebih sulit untuk diidentifikasi.
\end{abstract}

Kata Kunci: Audio Forensik, Voice Changer, Rekaman Suara, Pitch, Formant, Spectogram

\begin{abstract}
Audio forensics is one of the sciences that mnyandingkan between science and scientific methods in the process of sound recording analysis to assist and support the disclosure of a crime required in the trial process. The ITE Act No.19 of 2016 states that voice recording is one of the most valid digital instruments and can be used as an indictment. Voice recordings that are digital evidence are extremely easy and prone to be manipulated, either intentionally or unintentionally. In this research, there is an analysis related to the similarity level between the voice changer voice recording with the original sound recordings using pitch, formant and spectogram analysis. The sound recording that is analyzed are two types of sound recording, namely male voice and female voice. Voice recording of voice changer and original sound recording, extracted using praat tools then the information obtained is analyzed by pitch, formant and spectrogram analysis using gnumeric tools. This study resulted in the analysis of voice changer voice recording with original sound recording using pitch, formant and spectrogram statistical analysis, voice changer A voice recording has the highest level of resemblance with original sound recording in low pitch position, while other voice changer more difficult to be identified
\end{abstract}

Keywords: Audio forensics, Voice Changer, Sound Recording, Pitch, Formant, Spectogram

\section{PENDAhuluaN}

Teknologi smartphonepada beberapa tahun ini mengalami perkembangan yang begitu pesatnya. Indonesia menjadi salah satu negara dengan pengguna smartphone terbesar ke empat setelah China, India dan Amerika. Menurut lembaga riset digital marketing Emarketer pada tahun 2018 jumlah pengguna smartphone aktif di Indonesia diperkirakan akan mencapai lebih dari 100 juta orang.

Perkembangan yang terjadi tidak hanya pada teknologi smartphone-nya saja, tapi sistem aplikasi pendukung pada smartphone tersebut juga ikut berkembang dengan cepat. Salah satunya dalam teknologi perekam suara.
Rekaman suara sering digunakan oleh seseorang untuk mengabadikan suatu percakapan secara langsung maupun melalui telpon. Sehingga pada praktiknya, rekaman suara dijadikan barang bukti yang dapat menguatkan dakwaan penegak hukum ketika proses persidangan.

Dalam Undang-Undang ITE No 19 Tahun 2016 menyebutkan bahwa rekaman suara merupakan salah satu alat bukti, sebagai mana yang dijelaskan dalam Pasal 1.

Hanya saja rekaman suara tidak dapat digunakan menjadi barang bukti tanpa melewati proses analisis yang cukup panjang, yang dilakukan oleh seorang ahli dalam bidang audio forensik. AlAzhar Nuh, (2011) menyebutkan dalam bukunya 
Audio Forensics: Theory and Analysis bahwa rekaman suara dapat dianalisis melalui parameter pitch, formant dan spectrogram. Komponen ini dapat digunakan untuk mengidentifikasi karakteristik suara seseorang untuk kepentingan voice recognition dengan menggunakan potongan dari rekaman suara yang dianalisis.

Pada praktiknya, rekaman suara merupakan barang bukti digital yang sangat rentan dan mudah untuk dimanipulasi. Dan salah satu dampak dari perkembangan teknologi dan aplikasi smartphone saat ini, terdapat fasilitas perubah suara atau yang disebut voice changer.

Lawlor dan Fagan (1999), mengatakan bahwa voice changermerupakan proses modifikasi/merubah suara laki-laki (male) dengan teknik tertentu sehingga terdengar seperti suara perempuan (female) dan begitu juga sebaliknya.

Penelitian ini menggunakan metode audio forensik yang telah banyak digunakan sebelumnya. Penelitian yang terbaru dilakukan oleh Aligarh (2016), melakukan penelitian untuk menciptakan lingkungan senatural mungkin, kondisi pengambilan, dan hasil dari metode forensik yang digunakan. Pada penelitian ini uji forensik terhadap barang bukti suara dilakukan dengan dengan menggunakan nilai pitch, formant, dan spectogram kemudian membandingkan suara barang bukti (unknown samples) dengan suara yang direkam sebagai pembanding (known samples).

Namun, penelitian terkait dengan rekaman suara voice changerjarang dilkaukan.Maka dari itu, penelitian ini dilakukan dengan tujuan untuk membandingkan tingkat kemiripan pitch, formant dan spectogram antara rekaman suara voice changer dengan rekaman suara asli,untuk mengetahui karakteristik rekaman suara yang dilakukan dengan satu aplikasi voice changer dan dibandingkan dengan rekaman suara asli serta untuk mengetahui karakteristik rekaman suara dari beberapa aplikasi voice changer yang dibandingkan dengan rekaman suara asli.

\section{TINJAUAN PUSTAKA}

Beberapa penelitian yang pernah dilakukan sebelumnya menjadi acuan dalam penelitian ini, diantaranya yaitu penelitian yang terbaru dilakukan oleh Aligarh (2016), melakukan penelitian untuk menciptakan lingkungan senatural mungkin, kondisi pengambilan, dan hasil dari metode forensik yang digunakan. Pada penelitian ini uji forensik terhadap barang bukti suara dilakukan dengan dengan menggunakan nilai pitch, formant, danspectogram kemudian membandingkan suara barang bukti (unknown samples) dengan suara yang direkam sebagai pembanding (known samples).Berdasarkan hasil dari analisis codec maka kondisi sepi dan semisepilah yang dapat dikatakan mirip dengan pelaku. Sementara lingkungan ramai sulit sekali untuk didapatkan kemiripannya, sehingga peluang kejahatan dapat dengan mudah dilakukan pada lingkungan ini.

Huizen, dkk (2016), melakukan penelitian tentang pengaruh sampling rate terhadap fitur pada rekaman suara, dengan menerapkan. Hasil pengujian perekaman langsung maupun rekaman melalui telepon didapatkan bahwa karekteristik fitur untuk sampling rate $8 \mathrm{KHz}, 16 \mathrm{KHz}$, dan $32 \mathrm{KHz}$ jika dibandingkan $16 \mathrm{KHz}$ dengan $32 \mathrm{KHz}$ mempunyai fitur yang sama, sedangkan $8 \mathrm{KHz}$ mempunyai fitur yang berbeda.

Huizen, (2017), melakukan penelitian tentang model evaluasi proses acquisisi pada rekaman percakapan (metadata) yang terpengaruh noise. Metodologi yang digunakan dengan membandingkan hasil ekstraksi tanpa noise dengan varian noise, dan diukur perubahan cirinya. Hasil pengujian didapatkan bahwa, untuk nilai SNR antara --5.4078 dB sampai -7.0632 dB, ciri masih dapat dikenali, sedangkan lebih dari $-7.0632 \mathrm{~dB}$ ciri telah mengalami perubahan.

\section{METODE PENELITIAN}

Pada penelitian ini, digunakan alur penelitian sebagai berikut:

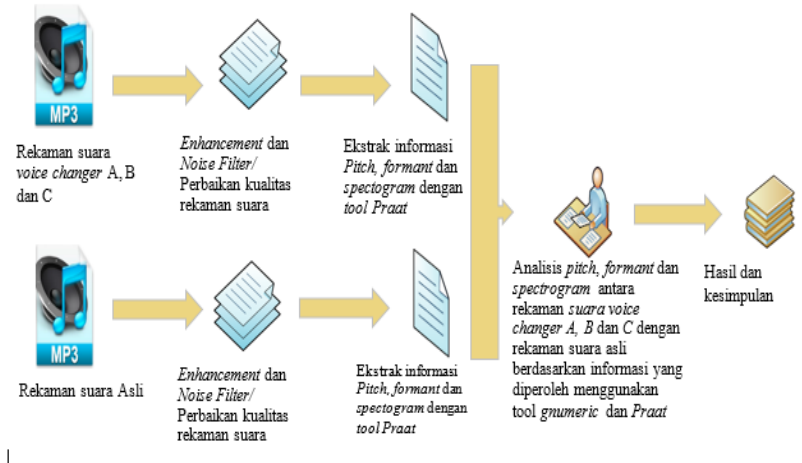

Gambar 1. Alur Penelitian

Adapun penjelasan terkait dengan metode penelitian ini yaitu sebagai berikut:

\subsection{Rekaman Suara}

Pada awal penelitian ini, terdapat 2 (dua) jenis rekaman yang akan di analisis, yaitu rekaman suara laki-laki dan suara perempuan yang telah dirubah dengan voice changer $A, B$ dan $C$. Suara rekaman terdiri dari masing-masing 11 kata.

Operating system yang digunakan pada waktu penelitian ini dibuat menggunakan Android v.5.0 sedangkan Voice changer yang dibandingkan pada saat penelitian ini dilakukan yaitu menggunakan:

* Voice changer A: Voice changer with effects version 3.2.10

* Voice changer B: Voice changer version 1.0.60

* Voice changer C: Voice changer version 1.1.1.

Dalam penelitian ini digunakan perangkat lunak (software) yaitu: 
a.Praat aplikasi ini digunakan dalam pencarian informasi dari perbandingan antara rekaman suara yang telah dirubah dengan aplikasi voice changer dan rekaman suara asli.

b. Gnumeric Spreadsheet yang akan digunakan untuk menghitung nilai formant pada setiap kata yang diucapkan. Nilai tersebut akan dimasukkan kedalam Gnumeric untuk dihitung nilai Anova, Likelihood Ratio dan Graphical distribution.

\subsection{Proses Enchancementdan Noise Filter}

Proses enhancement dan noise filter merupakan tahapan perbaikan kualitas dari rekaman suara. Terkadang hal ini perlu dilakukan apabila rekaman suara yang akan dianalisis memiliki tingkat noise yang cukup tinggi Al-Azhar Nuh, (2011). Namun apabila kualitas rekaman suara baik, maka proses ini tidak perlu dilakukan.

\subsection{Mengungkap Informasi Pitch, Formant dan Spectogram}

Pada tahap ini, rekaman suara yang akan dianalisis, dipecah menjadi kata-per kata. Hal ini bertujuan mempermudah dalam analisis. Kemudian masing-masing kata diekstrak menggunakan tools Praat untuk mendapatkan nilai pitch, formant dan spectogram.

\subsection{Analisis}

PadaAudio forensics: Theory and Analisys yaitu Analisis Satistik Pitch, Analisis Statistik Formant dan Bandwith, Analisis Graphical Disatribution dan Analisis Spectogram (Al-Azhar Nuh, 2011) menyebutkan bahwa tahapan analisis rekaman suara melalui beberapa tahapan sebagai berikut:

\subsubsection{Analisis Statistik Pitch}

Nilai pitch sangatlah bergantung pada tingkat intonasi dari suara yang diucapkan, semakin rendah intonasi subjek mengucapkan suatu kata, maka semakin rendah pula nilai pitch dari kata yang diucapkan. Sebaliknya, semakin tinggi intonasinya, maka akan semakin tinggi pula nilai pitch-nya (Wicaksono dan Prayudi, 2013). Karakter pitch dari masing-masing suara dibandingkan pada nila pitch minimum, nilai pitch maksimum dan nilai pitch mean (rata-rata). Dari perbedaan nilai statistik pitch inilah yang nantinya dapat membantu menilai tingkat kemiripan dari rekaman suara(Al-Azhar Nuh, 2011).

\subsubsection{Analisis Statistik Formant dan Bandwith}

Pada tahapan analisis statistik formant dan bandwith perlu dilakukan 2 jenis analisis, yaitu:

\section{a. Analisis Anova}

Al-Azhar Nuh (2011), mengatakan dalam menarik kesimpulan analisis Anova, formant yang dibutuhkan paling tidak formant 1, 2, dan 3 yang harus dianalisis. Jika 2 (dua) di antara formant 1,2 , dan 3 menunjukkan Accepted maka hal tersebut sudah cukup untuk menarik kesimpulan IDENTIK berdasarkan Anova. Hasil dari Analisa anova ini akan menunjukkan perbedaan antara 2 (dua) kelompokdata pada masing masing formant, yang ditandai dengan perbandingan perbandingan ratio $\mathrm{F}$ dan $\mathrm{F}$ critical, dan nilai probability $\mathrm{P}$ (P-Value). Jika nilai $F$ lebih kecil dari $F$ critical, dan nilai probability $\mathrm{P}$ lebih besar dai 0,5 maka dapat ditarik kesimpulan bahwa kedua kelompok kata yang dianalisa antara suara yang telah dirubah dengan voice changer dengan suara asli memiliki kemiripan (accepted), kesimpulan ini memiliki tingkat kofidensi sebesar 95\% (Al-Azhar Nuh, 2011).

\section{b. Analisis Likelihood Ratio}

Analisislikelihood ratio digunakan untuk memperkuat hasil analisis Anova yang didapat sebelumnya dengan memberikan statement hipotesis mendukung penuntutan/perlawanan, karena anlisis likelihood ratio ini dapat menjelaskan seberapa levelanalisis yang mendukung hipotesis penuntutan maupun hipotesis perlawanan. Formula perhitungan Likelihood Ratio dapat dilihat pada gambar 2.

\begin{tabular}{|l|}
$L R=\frac{p\left(E \mid H_{\rho}\right)}{p\left(E \mid H_{d}\right)}$ \\
di mana: \\
$p\left(E \mid H_{\rho}\right)$ adalah hipotesis tuntutan (prosecution), yaitu known dan unknown samples \\
berasal dari orang yang sama. \\
$p\left(E \mid H_{d}\right)$ adalah hipotesis perlawanan (defense), yaitu known dan unknown samples berasal \\
dari orang yang berbeda. \\
$p\left(E \mid H_{p}\right)$ berasal dari p-value Anova, sedangkan $p\left(E \mid H_{d}\right)=1-p\left(E \mid H_{\rho}\right)$
\end{tabular}

Gambar 2. Bagan Formula Likelihood Ratio Sumber: Paper Audio Forensic: Theory and Analysis

Dimana :

- $\quad p(\mathrm{E} \mid \mathrm{Hp})$ adalah hipotesis tuntutan (prosecution), yaitu known dan unknown samples berasal dari orang yang sama.

- $\quad p(\mathrm{E} \mid \mathrm{Hd})$ adalah hipotesis perlawanan (defense), yaitu known dan unknownsamples berasal dari orang yang berbeda.

$p(\mathrm{E} \mid \mathrm{Hp})$ berasal dari $p$-value Anova, sedangkan $p$ $(\mathrm{E} \mid \mathrm{Hd})=1-p(\mathrm{E} \mid \mathrm{Hp})$ Jika LR $>1$, maka hal ini mendukung $p(\mathrm{E} \mid \mathrm{Hp})$, sebaliknya jika LR $<1$, maka $p(\mathrm{E} \mid \mathrm{Hd})$ yang didukung. Untuk itu, haruslah nilai $p$ (E $\mid \mathrm{Hp})>0.5$ untuk dapat menyimpulkan bahwa suara barang bukti (unknown) dan suara pembanding (known) berasal dari orang yang sama (IDENTIK).

Besarnya ratio LR diikuti dengan verbalstatement untuk menjelaskan nilai LR tersebut, seperti pada table berikut: 
Tabel 1.Verbal statement mendukung hipotesis tuntutan

\begin{tabular}{|c|c|c|c|}
\hline LR & $\operatorname{LR}(\log )$ & Verbal Statement & Keterangan \\
\hline$>10.000$ & $>4$ & Very strong evidence to support & \multirow{5}{*}{$\begin{array}{c}\text { Mendukung } \\
\text { hipotesis } \\
\text { tuntutan } \\
p(\mathrm{E} \mid \mathrm{H} p)\end{array}$} \\
\hline $1.000-10.000$ & 3-4 & Strong evidence to support & \\
\hline $100-1.000$ & $2-3$ & Moderately strong evidence to support & \\
\hline $10-100$ & $1-2$ & Moderate evidence to support & \\
\hline $1-10$ & $0-1$ & Limited evidence to support & \\
\hline
\end{tabular}

Sumber: Forensic Speaker Identification(Rose, 2002)

Tabel 2.Verbal Statement mendukung hipotesis perlwanan

\begin{tabular}{|c|c|c|c|}
\hline LR & $\mathrm{LR}(\log )$ & Verbal Statement & Keterangan \\
\hline $1-0.1$ & $0-(-1)$ & Limited evidence against & \multirow{5}{*}{$\begin{array}{l}\text { Mendukung } \\
\text { hipotesis } \\
\text { perlwanan } \\
p(\mathrm{E} \mid \mathrm{H} d)\end{array}$} \\
\hline $0.1-0.01$ & $-1-(-2)$ & Moderate evidence against & \\
\hline $0.01-0.001$ & $-2-(-3)$ & Moderately strong evidence against & \\
\hline $0.001-0.0001$ & $-3-(-4)$ & Strong evidence against & \\
\hline$<0.0001$ & $>(-4)$ & Very strong evidence against & \\
\hline
\end{tabular}

Sumber: Forensic Speaker Identification(Rose, 2002)

Dari kedua tabel di atas, diketahui bahwa untuk mendapatkan dukungan terhadap hipotesis penuntutan (rekaman suara yang telah dirubah dengan voice changer dan suara asliberasal dari orang yang sama) haruslah LR > 1, di mana semakin besar nilai LR akan semakin baik dan kuat untuk verbal statement-nya(Al-Azhar Nuh, 2011).

\subsection{Analisis Graphical Distribution}

Analisis graphical distribution ini bertujuan untuk menggambarkan dalam bentuk grafis tingkat penyebaran (distribusi) masing masing nilai formantyang telah diperoleh sebelumnya, biasnaya digambarkan dengan perbandingan antara formant 1 vs formant 2 dan formant 2 vs formant 3(Al-Azhar Nuh, 2011).

\subsection{Analisis Spectogram}

Tahap analisis spectogram ini dilakukan demi melihat pola khas yang terdapat pada masing-masing formant rekaman suara. Pada analisis spectrogramakan terlihat tingkat energi masing masing formant. Apabila pada pengucapan suku kata tertentu dari suara yang telah dirubah dengan voice changer dan suara asli tidak menunjukkan suatu perbedaan yang signifikan maka dapat disimpulkan bahwa pengucapan kata-kata tersebut memiliki kesamaan spectrogram (Al-Azhar Nuh, 2011).

\subsection{Hasil Analisis Kesimpulan}

Pada tahapan akhir ini terdapat kesimpulan yang memuat hasil analisis rekaman suara voice changer dan rekaman suara asli. Dari analisis ini akan terlihat perbedaan antara voice changer $A, B$ dan $C$ baik dengan metode meninggikan pitch (high ptich) maupun merendahkan pitch (low pitch).Sehingga dapat diketahui apa penyebab perbedaan hasil analisis tersebut.

\section{HASIL DAN PEMBAHASAN}

Pada pelitian ini terdapat dua jenis rekaman suara yaitu rekaman suara laki-laki dan rekaman suara perempuan, kata yang diucapkan pada masingmasing rekaman suara tersebut terdiri dari 11 kata. Pada rekaman suara laki-laki berbunyi "analisis audio forensik untuk mengetahui tingkat kemiripan pitch, formant dan spectogram".Dan pada rekaman suara perempuan berbunyi " Listening section, in this the test you will have the chance to show how well you understand spoken english".

Sebelum melakukan analisis perlu diperhatikan bahwa rekaman suara yang akan di analisis memiliki sampling rate yang sama, agar tidak mempengaruhi hasi penelitian kedepannya (Huizen, dkk, 2015).

Adapun hasil analisis didapatkan perbandingan antara voice changerA, $B$ dan $C$ dengan rekaman suara asli sebagai berikut:

a. Analisis rekaman suara laki-laki

Tabel 3. Hasil Analisisvoice changerA (high pitch) dengan rekaman suara asli

\begin{tabular}{|l|l|l|l|}
\hline & Input (Kata) & Identik & Tidak Identik \\
\hline Analisis Pitch & 11 & 0 & 11 \\
\hline Analisis Anova & 11 & 6 & 5 \\
\hline Analisis Likelihood Ratio & 11 & 6 & 5 \\
\hline Analisis Graphical Distribution & 11 & 8 & 3 \\
\hline Analisis Spectogram & 11 & 8 & 3 \\
\hline
\end{tabular}

Tabel 4. Hasil Analisisvoice changerA (low pitch) dengan rekaman suara asli

\begin{tabular}{|l|l|l|l|}
\hline & Input (Kata) & Identik & Tidak Identik \\
\hline Analisis Pitch & 11 & 0 & 11 \\
\hline Analisis Anova & 11 & 5 & 6 \\
\hline Analisis Likelihood Ratio & 11 & 5 & 6 \\
\hline Analisis Graphical Distribution & 11 & 9 & 2 \\
\hline Analisis Spectogram & 11 & 11 & 0 \\
\hline
\end{tabular}

Tabel 5. Hasil Analisisvoice changer B (high pitch) dengan rekaman suara asli

\begin{tabular}{|l|l|l|l|}
\hline & Input (Kata) & Identik & Tidak Identik \\
\hline Analisis Pitch & 11 & 0 & 11 \\
\hline Analisis Anova & 11 & 3 & 8 \\
\hline Analisis Likelihood Ratio & 11 & 3 & 8 \\
\hline Analisis Graphical Distribution & 11 & 9 & 2 \\
\hline Analisis Spectogram & 11 & 7 & 4 \\
\hline
\end{tabular}

Tabel 6. Hasil Analisisvoice changer B (low pitch) dengan rekaman suara asli

\begin{tabular}{|l|l|l|l|}
\hline & Input (Kata) & Identik & Tidak Identik \\
\hline Analisis Pitch & 11 & 0 & 11 \\
\hline Analisis Anova & 11 & 3 & 8 \\
Analisis Likelihood Ratio & 11 & 3 & 8 \\
\hline Analisis Graphical Distribution & 11 & 8 & 3 \\
\hline Analisis Spectogram & 11 & 11 & 0 \\
\hline
\end{tabular}

Tabel 7. Hasil Analisisvoice changer C (high pitch) dengan rekaman suara asli

\begin{tabular}{|l|l|l|l|}
\hline & Input (Kata) & Identik & Tidak Identik \\
\hline Analisis Pitch & 11 & 0 & 11 \\
\hline Analisis Anova & 11 & 4 & 7 \\
\hline Analisis Likelihood Ratio & 11 & 4 & 7 \\
\hline Analisis Graphical Distribution & 11 & 7 & 4 \\
Analisis Spectogram & 11 & 8 & 3 \\
\hline
\end{tabular}


Tabel 8. Hasil Analisisvoice changer C (low pitch) dengan rekaman suara asli

\begin{tabular}{|l|l|l|l|}
\hline & Input (Kata) & Identik & Tidak Identik \\
\hline Analisis Pitch & 11 & 0 & 11 \\
\hline Analisis Anova & 11 & 4 & 7 \\
\hline Analisis Likelihood Ratio & 11 & 4 & 7 \\
\hline Analisis Graphical Distribution & 11 & 8 & 3 \\
\hline Analisis Spectogram & 11 & 9 & 2 \\
\hline
\end{tabular}

Berdasarkan tabel di atas, voice changerApada rekaman suara laki-laki memiliki tingkat identik yang paling tinggi, ini menunjukkan bahwa voice changer Apada rekaman suara laki-laki memiliki kemungkinan yang cukup besar untuk dapat diidentifikasi apabila terdapat barang bukti audio yang menggunakan voice changerA. Sedangkan voice changer $B$ dan $C$ pada rekaman suara laki-laki memiliki kemungkinan kecil untuk dapat diidentifikasi. Hasil ini diperoleh dari jumlah kata yang identik dari keseluruhan analisis pada rekaman suara voice changer $A, B$ dan $C$ yang dibandingkan dengan rekaman suara asli. Hasil ini bisa dilihat pada gambar 3 berikut

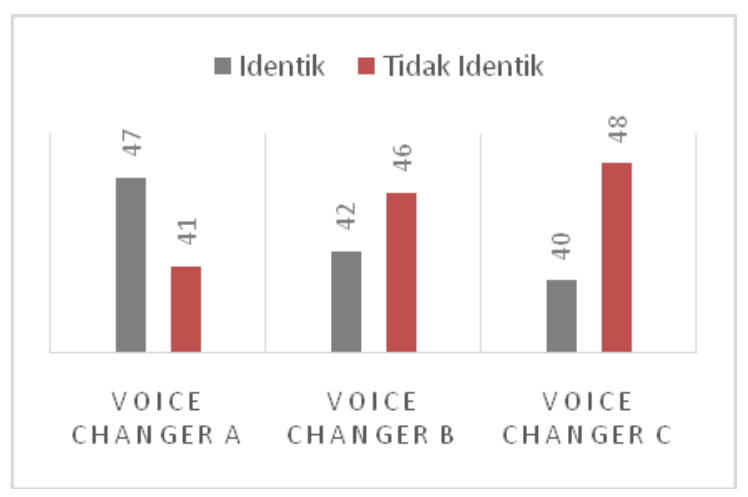

Gambar 3 Hasil Perbandingan Tingkat Kemiripan

Sedangkan analisis pada rekaman suara voice changer dengan metode merendahkan pitch(low pitch)pada rekaman suara laki-laki cenderung memiliki kemungkinan yang cukup besar untuk dapat diidentifikasi bila dibandingkan dengan analisis pada rekaman suara voice changer dengan metode meninggakan pitch (high pitch), seperti yang terlihat pada gambar 4 berikut.

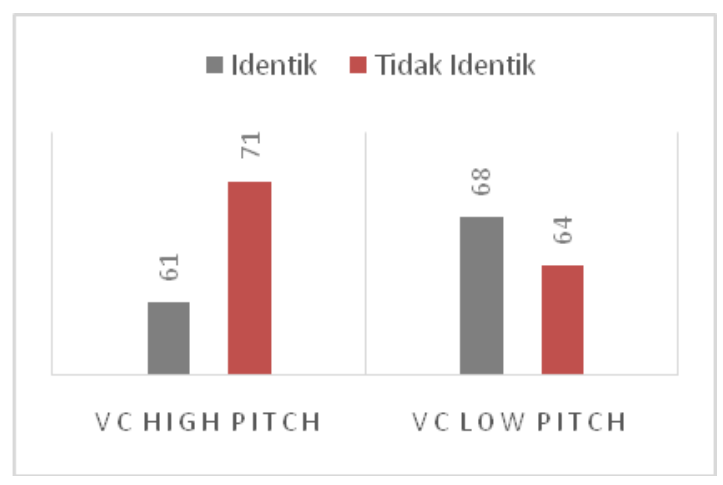

Gambar 4 Perbandingan Tingkat Kemiripan $V C$ High Pitch dengan VC Low Pitch b. Analisis rekaman suara perempuan

Tabel 9. Hasil Analisis voice changerA (high pitch) dengan rekaman suara asli

\begin{tabular}{|l|l|l|l|}
\hline & Input (Kata) & Identik & Tidak Identik \\
\hline Analisis Pitch & 11 & 0 & 11 \\
\hline Analisis Anova & 11 & 5 & 6 \\
\hline Analisis Likelihood Ratio & 11 & 5 & 6 \\
\hline Analisis Graphical Distribution & 11 & 5 & 6 \\
\hline Analisis Spectogram & 11 & 8 & 3 \\
\hline
\end{tabular}

Tabel 10. Hasil Analisis voice changerA (low pitch) dengan rekaman suara asli

\begin{tabular}{|l|l|l|l|}
\hline & Input (Kata) & Identik & Tidak Identik \\
\hline Analisis Pitch & 11 & 0 & 11 \\
\hline Analisis Anova & 11 & 7 & 4 \\
\hline Analisis Likelihood Ratio & 11 & 7 & 4 \\
\hline Analisis Graphical Distribution & 11 & 9 & 2 \\
\hline Analisis Spectogram & 11 & 11 & 0 \\
\hline
\end{tabular}

Tabel 11. Hasil Analisis voice changerB (high pitch) dengan rekaman suara asli

\begin{tabular}{|l|l|l|l|}
\hline & Input (Kata) & Identik & Tidak Identik \\
\hline Analisis Pitch & 11 & 0 & 11 \\
\hline Analisis Anova & 11 & 2 & 9 \\
\hline Analisis Likelihood Ratio & 11 & 2 & 9 \\
\hline Analisis Graphical Distribution & 11 & 6 & 5 \\
\hline Analisis Spectogram & 11 & 7 & 4 \\
\hline
\end{tabular}

Tabel 12. Hasil Analisis voice changerB(low pitch) dengan rekaman suara asli

\begin{tabular}{|l|l|l|l|}
\hline & Input (Kata) & Identik & Tidak Identik \\
\hline Analisis Pitch & 11 & 0 & 11 \\
\hline Analisis Anova & 11 & 3 & 8 \\
\hline Analisis Likelihood Ratio & 11 & 3 & 8 \\
\hline Analisis Graphical Distribution & 11 & 8 & 3 \\
\hline Analisis Spectogram & 11 & 9 & 2 \\
\hline
\end{tabular}

Tabel 13. Hasil Analisis voice changerC(highpitch) dengan rekaman suara asli

\begin{tabular}{|l|l|l|l|}
\hline & Input (Kata) & Identik & Tidak Identik \\
\hline Analisis Pitch & 11 & 0 & 11 \\
\hline Analisis Anova & 11 & 1 & 10 \\
\hline Analisis Likelihood Ratio & 11 & 1 & 10 \\
\hline Analisis Graphical Distribution & 11 & 7 & 4 \\
\hline Analisis Spectogram & 11 & 6 & 5 \\
\hline
\end{tabular}

Tabel 14. Hasil Analisis voice changerC (low pitch) dengan rekaman suara asli

\begin{tabular}{|l|l|l|l|}
\hline & Input (Kata) & Identik & Tidak Identik \\
\hline Analisis Pitch & 11 & 0 & 11 \\
\hline Analisis Anova & 11 & 4 & 7 \\
\hline Analisis Likelihood Ratio & 11 & 4 & 7 \\
\hline Analisis Graphical Distribution & 11 & 8 & 3 \\
\hline Analisis Spectogram & 11 & 9 & 2 \\
\hline
\end{tabular}

Berdasarkan ujicoba yang dilakukan pada rekaman suara perempuan menunjukkan bahwa rekaman suara voicechanger $A$ memiliki tingkat kemiripan yang paling tinggi dengan rekaman suara asli pada posisi merendahkan pitch (low pitch), Sedangkan voice changer $B$ dan Cmemiliki kemungkinan terkecil untuk dapat di identifikasi. Hasil ini diperoleh dari jumlah kata yang identik dari keseluruhan analisis pada rekaman suara voice changer $A, B$ dan $C$ yang dibandingkan dengan rekaman suara asli. Hasil ini bisa dilihat pada gambar 5 berikut. 


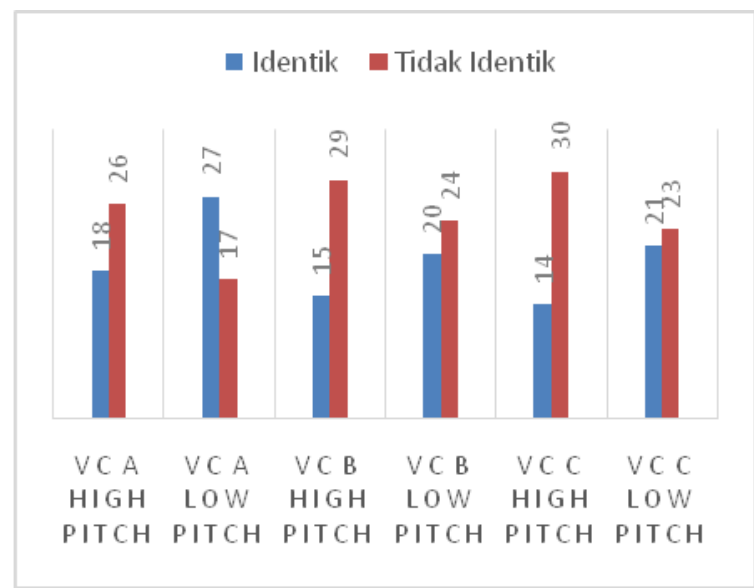

Gambar 5 Perbandingan Tingkat Kemiripan VC High Pitch dengan VC Low PitchPada Rekaman Suara Perempuan

Berdasarkan penelitian yang dilakukan ini voice changer dapat digunakan untuk merekayasa rekaman suara dengan dua cara yaitu meninggikan pitch (high pitch) dan merendahkan pitch(low pitch), berdasarkan ujicoba yang dilakukan menunjukkan bahwa rekaman suara voicechangerA memiliki tingkat kemiripan yang paling tinggi dengan rekaman suara asli pada posisi merendahkan pitch (low pitch)baik pada rekaman suara laki-laki ataupun rekaman suara perempuan, sedangkan voice changer yang lain lebih sulit untuk di identifikasi. Penyebab rekaman suara voice changer memiliki tingkat kemiripan yang berbeda disebabkan karena perbedaan algoritma/parameter timestretching dan pitch shifting yang digunakan pada masing-masing voice changer.

\section{KESIMPULAN DAN SARAN}

Berdasarkan hasil yang didapatkan pada pembahasan maka penelitiandapat ditarik kesimpulan sebagai berikut:

1. Analisis pitch, formant dan spectogram dapat digunakan untuk melakukan analisis audio forensik yang terkait dengan rekaman suara voice changer.

2. Berdasarkan ujicoba yang dilakukan menunjukkan bahwa rekaman suara voicechanger $A$ memiliki tingkat kemiripan yang paling tinggi dengan rekaman suara asli pada posisi merendahkan pitch (low pitch) baik pada rekaman suara laki-laki ataupun rekaman suara perempuan, sedangkan voice changer yang lain lebih sulit untuk diidentifikasi.

\footnotetext{
Adapun saran-saran yang perlu dikembangkan untuk penelitian terkait voice changer lebih lanjut dalah sebagai berikut:

1. Perlu dilakukan penelitian terkait barang bukti rekaman suara yang dirubah menggunakan voice
}

changer yang sulit untuk diidentifikasi seperti voice changer $B$ dan $C$ dan bagaimana solusinya.

2. Pada penelitian terkait voice changer selanjutnya, dilakukan dengan barang bukti suara yang di analisis lebih dari satu jenis rekaman suara, minimal menggunakan tiga jenis rekaman suara yang berbeda dengan masing-masing 20 kata.

\section{DAFTAR PUSTAKA}

AL-AZHAR NUH, M. 2011. AUDIO FORENSIC : Theory and Analysis, 1-38.

ALIGARH, A., HIDAYANTO, C., SI, S., \& KOM, M. 2016. Implementasi Metode Forensik dengan Menggunakan Pitch, Formant, dan Spectrogram untuk Analisis Kemiripan Suara Melalui Perekam Suara Telepon Genggam Pada Lingkungan yang Bervariasi, 5(2).

HUIZEN, R. R., KETUT, N., ARI, D., \& HOSTIADI, D. P. 2015. Analisis Pengaruh Sampling Rate Dalam Melakukan Identifikasi Pembicara Pada Rekaman Audio, 9-10.

HUIZEN, R. R., KETUT, N., ARI, D., \& HOSTIADI, D. P. 2016. Model Acquisisi Rekaman Suara Pebanding Di Audio Forensik, 6-7.

HUIZEN, R. R., KETUT, N., ARI, D., \& HOSTIADI, D. P. 2017. Model Evaluasi Rekaman Percakapan Di Audio Forensik, 133-140.

LAWLOR, B., \& FAGAN, A. D. 1999. A novel efficient algorithm for voice gender conversion. ICPhS, 77-80.

ROSE, P. 2002. Forensic Speaker Identification. SciencesNew York (Vol. 20025246). https://doi.org/10.1201/9780203166369.

WICAKSONO, G., \& PRAYUDI, Y. 2013. Teknik Forensika Audio Untuk Analisa Suara Pada Barang Bukti Digital. Semnas Unjani. 